\title{
RESET
}

Recherches en sciences sociales sur Internet

Des classes sociales 2.0 ?

\section{Elective Affinities 2.0?}

A Bourdieusian Approach to Couple Formation and the Methodology of E-Dating

Des affinités électives 2.0? Une approche bourdieusienne de la formation des couples à travers les rencontres en ligne

\section{Andreas Schmitz}

\section{(2) OpenEdition}

\section{Journals}

Electronic version

URL: http://journals.openedition.org/reset/141

DOI: $10.4000 /$ reset.141

ISSN: 2264-6221

Publisher

Association Recherches en sciences sociales sur Internet

Electronic reference

Andreas Schmitz, «Elective Affinities 2.0? », RESET [Online], 1 | 2012, Online since 30 December 2012 connection on 01 May 2019. URL : http://journals.openedition.org/reset/141 ; DOI : 10.4000/reset.141

This text was automatically generated on 1 May 2019.

(c) Association Recherches en sciences sociales sur Internet 


\title{
Elective Affinities 2.0?
}

\author{
A Bourdieusian Approach to Couple Formation and the Methodology of \\ E-Dating \\ Des affinités électives 2.0? Une approche bourdieusienne de la formation des \\ couples à travers les rencontres en ligne
}

\section{Andreas Schmitz}

\section{Introduction}

1 Ten years after his death, Pierre Bourdieu can be called a 'modern classic'. ${ }^{1}$ His work is widely received amongst sociologists and in different related fields of science. However, there are several aspects of his research program that Bourdieu treated in an implicit way, and which need elaboration before one can use its full analytic potential. One example can be found in the mechanisms that underlie partnership formation.

Although Bourdieu addressed partnership formation processes, he did not develop a "general theory of marital exchange relations in differentiated societies" (Bourdieu, 2002: 234), nor did he devote himself to the empirical "minutiae of interactions" (Bourdieu, 2001 : 35). Viewing "acts of co-option" (Bourdieu, 1984 : 241) primarily from a perspective of dispositions for lifestyle similarity, Bourdieu was not particularly interested in the processual and intersubjective character of mating, or the genderspecific resources taking effect in form of reciprocal evaluation and rating practices. Hence, a superficial reception of Bourdieu's work might suggest a quasi-deterministic model of mating. One may conclude that, similar to the process of selecting a cultural commodity, men (or women) choose women (or men) with similar positions and lifestyles in the social space (Nagel, Ganzeboom \& Kalmijn, 2011). The result of such an oversimplified process would consist only of $a b$ ovo homogenous couple configurations, that is, exclusively dyads that consist of agents with the same lifestyle. This idea is not a great deal more substantial than a cultural version of the saying 'birds of a feather flock together'. An explicit theoretical elaboration seems necessary, as such a reception does 
not represent an exhaustive application of Bourdieu's perspective, nor would it represent an adequate analytical approach to empirical mating processes.

The aim of this paper is to develop a framework of partnership formation based on a comprehensive reception of Bourdieu's works, and to thereby provide a starting point for empirical assessments. The mechanism of homophilous lifestyle preferences, which seemingly automatically leads to homogenous relationships, will be extended applying the consideration that mating takes place as an interactional process where genderspecific heterophilous preferences and resources also play a role and (partially) heterogeneous couples may emerge. Therefore, a conceptualization of 'mating as reciprocal classification processes' will be suggested, elaborating on Bourdieu's work. This conceptualization includes lifestyle similarity preferences, but also relational equivalency preferences that do not refer to lifestyle similarity but to particular exchange relations. The theoretical framework and its methodological implications will be illustrated by means of data taken from a major German online dating provider.

Online dating can be discussed in the context of dissolution or reproduction of social classes (cf. Blossfeld 2009; Sautter, Tippett \& Morgan, 2010). But it has also proven to be a valuable source of data for mating research (e.g. Fiore \& Donath, 2005 ; Ellison, Heino \& Gibbs, 2006 ; Bergström, 2011 ; Zillmann, Schmitz \& Blossfeld, 2011 ; Skopek, 2012). It may seem very specific in terms of sui generis characteristics or processes: however, the dyadic nature of encounters, the pressure to apply strategies of self-presentation and choice, the high degree of competition, and the 'administrative' management of a plethora of potential partners make online dating an ideal-type market, one that allows for a detailed study of classificatory processes. This new dyadic data, and the methodical challenge of its analysis, has been ignored in (online dating) research until now. After explaining the data's structure and its operationalization, a simplified illustration of the empirical application of the construction of classificatory mating practices is presented and discussed against the background of a refined Bourdieusian model of partnership formation. The proposed examination may also support the general idea that homogeneity is reinforced, not undermined, by the technical conditions of online interaction.

\section{Classification through Social Space and Habitus}

5 Geographic and contextual selectivity has been central to research on mating (Bozon \& Héran, 1989). In Bourdieu's view, the agents' probability of physical encounter is conditioned by social space in the first place ; it is greater the nearer each other agents are situated, i.e. the more similarities they have regarding their capital resources and the corresponding habitus. The social space conditions the geographic space in such a way that agents with different social status are less likely to meet than agents with the same social status. But it is not just the objective conditions that enable or restrict the agents' access to specific geographic spaces; lifestyles as expressions of a position in the social space also structure the selection of foci of encounter, as their particular use strongly depends on the agent's (dis)positions (Bourdieu, 1984). Social classification as induced by social and geographic space becomes intensified in situations of interaction. Disparities in lifestyle complicate the agents' conversations, their interactions, indeed their very being together, as the common basis of decoding symbolic expressions is absent. 
6 Bourdieu comprehended "acts of cooption" as "sign-reading operations (particularly visible in first encounters) through which a habitus confirms its affinity with (an) other habitus" (Bourdieu, 1984: 243). Given reciprocal habitus affirmation, provided by reciprocal symbolic decoding, interactions are perceived as harmonious, leading to a mutual feeling of sympathy and reciprocal 'existential certainty'. This does not mean that rational actors consciously try to optimize their 'cultural fit' to a potential partner, as rational action theories assume with regard to a partner's income, education etc. Rather, mating preferences in Bourdieu's view are expressions of underlying dispositions (Bourdieu, 2001: 37). Hence, in his model of practice, it is not conscious mating preferences, but rather taste - the practical expression of habitus as well as the mode of cultural decoding - which explains the realization of a partnership. Upon experiencing a congruent habitus - thanks to taste -, the involved agents often perceive their encounter as an accident of fate, and fail to recognise its socio-spatial prerequisites. An incompatibility of tastes, in contrast, renders social contact more difficult, and creates little mutual attraction. Taste, according to Bourdieu, takes effect as an incorporated 'sense of one's place', i.e. as a position-dependent sense of one's social position, as well as that of a potential partner. This sense of one's place is "at the same time a sense of the place of others, and, together with the affinities of habitus experienced in the form of personal attraction or revulsion, is at the root of all processes of cooptation, friendship, love, association, etc., and thereby provides the principle of all durable alliances and connections, including legally sanctioned relationships" (Bourdieu, $1987: 5$ ). The position in social space and the corresponding habitus are linked to a sense for an agent's status that becomes manifest in the perception of other people, and influences the willingness and ability to interact with them. The taste for a partner, therefore, not only describes the socio-spatial origins of partnership preferences, but it "is what brings together things and people that go together" (Bourdieu, $1984: 241$ ). The potency of taste is by no means confined to decoding similarities, but is also reflected in the (joint) dissociation of alternative lifestyles: "Aversion to different lifestyles is one of the strongest barriers between the classes ; class endogamy is evidence of this." (Bourdieu, $1984: 56)$. Hence, the everyday application of subjective taste is reflected objectively in a reproduction of objective structures in the form of homogenous relationships. ${ }^{2}$

7 Reciprocal decoding, experiencing and classifying do not instantaneously emerge and result in a relationship - but they need time and take the form of a process. The case of first encounter, which often takes the form of flirting, is of particular relevance for reciprocal decoding processes, as its success and failure condition subsequent interactions. A conversation often revolves around questions of everyday life and at the same time allows a (not necessarily conscious) 'clandestine scrutiny' of habitus congruency. In these processes of common 'position finding', practices, as well as agents and their characteristics, are rated and classified according to differentiated and differentiating taste, because "taste classifies, and classifies the classifier. Social subjects, classified by their classifications, distinguish themselves by the distinctions they make, between the beautiful and the ugly, the distinguished and the vulgar, in which their position in the objective classifications is expressed or betrayed." (Bourdieu, 1984:6). Agents who are classified by their position in social space classify themselves and others indirectly through everyday practices, and directly by practices of (non-)interactions. But, in contrast to an inanimate consumer good, a relationship (in the Western modernity) is based on consent and the mutual interest of two agents, meaning that 
processes of mating do not merge into one-sided practices, but rather take the form of reciprocal classification practices, a perspective that will be advanced in the next section.

\section{Some Elaborations toward a General Model of Reciprocal Classifying in Mating}

Reducing Bourdieu's theory to lifestyle-homophily as the only mode of mating obscures possible deviations from both empirical homophily and homogeneity, as well as from its processual and gender-specific dimensions. His analytical tools in fact open up the potential to conceptualize the relational position of two potential partners, given the context of a 'partner market' within a surrounding social space. Similarly to social classes, emerging dyadic configurations can be relationally assessed by analyzing the "structure of relations between all the pertinent properties" (Bourdieu, 1984 : 106). This view avoids a priori definitions of which particular resource is generally relevant for the development of couples, and instead motivates empirical analyses of which trait relations may underlie reciprocal classification processes. Therefore, mating processes can be conceptualized in their development and dyadic variability utilizing the analytical power of the habitus-field theory. This also opens up the possibility of non-lifestyle-based preferences and mating results.

9 These considerations implicate accentuating three interdependent issues for an elaborated Bourdieusian theory of mating processes. Firstly, Bourdieu did not put particular emphasis on variable individual preferences, as he mostly relied on homophily as the dominant mode of interaction willingness. Although the fundamental significance of gender for mating processes did find consideration in his work (Bourdieu, 2001 ; 2002), the gender-specific character of resources and their implication for mating preferences received little attention. Secondly, Bourdieu barely discussed interactional issues systematically, such as intersubjective processes of negotiation and consensus-finding, as he saw the conditions and outcomes of interactions as being determined by the social space. Thirdly, Bourdieu did not focus on the possibility of heterogeneous couple configurations, as he focused on the reproduction of the social space in his works. Hence, the theoretical task undertaken in the following sections is the analytical location of heterophilous preferences and resulting heterogenous couples and underlying interactional processes - within a Bourdieusian framework of mating as reciprocal classification. Subsequently these considerations will be transferred in the concept of equivalency in addition to reciprocal classification.

\section{Heterophily and Heterogeneity}

10 In Bourdieu's work, interaction in general - and couple formation in particular - is discussed according to lifestyle similarity preferences, which have an a priori status (Bottero, 2009: 404). Therefore, a Bourdieusian may feel compelled to explain mating results by 'horizontal mating preferences', that is, preferences for the same lifestyle. However, it is sometimes overlooked that Bourdieu also discussed heterophilous mating preferences (Bourdieu, 2001: 37). Skimming his work might suggest a perspective that restricts itself to a narrow conceptualization of interactional preferences (e.g. King, 2000 : 423 ; Nagel, Ganzeboom \& Kalmijn, 2011). Such a narrow conception of habitus-based similarity preference, determined by socio-spatially similar positions, takes it for granted 
that the objective distance (the disparity regarding capital volume and capital composition) in the social space determines the subjective distance (the perceived willingness to interact) : even though this might correspond to reality in many cases, especially where homogeneity is a result of mating processes, it represents an inappropriate generalization from a process perspective.

11 Bourdieu himself rejected the 'meaningless usage of homophily', i.e. its usage independent of the social position of the preference holder (Bourdieu, $2002: 234$ ). Firstly, just as general tastes in a society show a hierarchical order, with more legitimate tastes in the higher classes, taste in mating can follow the same principle, with agents that can afford to act on their tastes, and agents that are forced to follow 'a taste of necessity'. second, the peculiarity of the propensity to show homophilous preferences is itself habitus-specific. Therefore, with the habitus concept, explanations of more or less heterophilous mating preferences are also possible. Bourdieu traced heterophilous mating preferences, such as age preferences or height preferences, back to their social conditions (Bourdieu, 2001: 37). Although implicit, like homophily, heterophily was treated by Bourdieu as rooted in objective constraints. The social space generally structures "aspirations by determining the extent to which they can be satisfied" (Bourdieu, 1973: 83) by an "adjustment of preference to the objective probabilities" (Bourdieu, 2001:37). These adjustments are also a function of objective or subjective trajectories: the mere expectation of a future position may relativize the connection between structure and aspiration, just as a realized objective promotion can be associated with an effect of hysteresis (Bourdieu, $1984: 142$ ).

Gender, as a basic trait of the habitus, which specifies the structure of preferences, is a core potential source for non-similarity-based mating processes. Bourdieu sees gender as an "absolutely fundamental dimension of the habitus that [...] modifies all the social qualities that are connected to the fundamental social factors" (Bourdieu, 1997, translated by Krais, 2006: 128). In processes of couple formation, there is even more significance in gender structuring the habitus of an agent, as well as conditions and forms of encounter. Both mating preferences and favorable capitals are gender-specifically structured and complementary to each other, as "a woman and a man do not sell themselves in the same way on the matrimonial market" (de Singly, 1987:197, own translation). Bourdieu (2001) interpreted preferential patterns as an expression of social conditions that foster women's disposition of a symbolic subordination to their partner, as they define themselves by their male partner's status. For Bourdieu, the male competition and gender-specific complementarities of age and height preferences are emanations of the 'male dominance' incorporated by both sexes, and become naturalized in everyday practices (Bourdieu, 2001).

13 Consequently, there can be a striking difference between the characteristics that are advantageous for men and women. Hence, it should be noted that a particular equality (e.g. the same educational qualification) can imply a dissimilarity in status, as the relevance of the manifest characteristic on the partner market differs for the sexes. A high formal educational qualification plays a less decisive or even restricting role for a woman's likelihood of success on the partner market, which may not be immediately obvious from a substantialist point of view. Another characteristic that often plays the role of a gender-specific resource is the level of physical attractiveness, as the amount of physicality in symbolic capital is greater in women than in men (Bourdieu, 2001 : 99). In the practice of evaluating a partner, the relevance of the lifestyle of a potential partner 
can be relativized by the physical attractiveness. One can conclude that, by their habitus, men and women differ by means of what traits they want to and can exchange with a potential mate as a position "does not only depend on the intrinsic level of resources but also on the sexual conformity of these capitals" (De Singly, 1987 : 197, own translation).

These considerations already question a direct relationship between homophily and homogeneity. Regardless of which dispositions underlie mating preferences, the mere presence of different (gender-specific) preferences can also extend the complexity of mating interactions and foster homogenous couple configurations. Lifestyles are empirically associated with age, education and attractivity but there is hardly a complete congruency between these traits in a social space. Hence, the impact of lifestyle-similarity preferences gets relativized, inasmuch as lifestyles and other traits do not correlate within the agents involved. Imagine a preferred lifestyle is scarce and available partners of the desired sex, age, appearance etc. show a different lifestyle, as one would ideally expect. Accordingly, it is just as incommensurate with logic and empirical reality that resulting couples necessarily share all attributes and are homogenous with regard to all traits. In order to widen the perspective for processes where such different mating preferences can generate different couples, one has to take into account the fields of interactions.

\section{Interaction}

In Bourdieu's view, an interaction is a medium where social similarity precipitates, induced by social space. He discusses interactions less systematically as an analytical level in their own right ; instead, with his habitus perspective, he abstracts from contingent situations of encounter and reciprocal classification, in order to avoid an 'interactional fallacy': "interacting individuals bring all their properties into the most circumstantial interactions, and their relative positions in the social structure (or in a specialized field) govern their positions in the interaction." (Bourdieu, 1984: 578-579). Because this structuralism dominates Bourdieu's perspective on interactions, his works do not feature an explicit discussion of processes of mutually interrelated actions and perceptions, which occupy an important position in mating. However, for an analysis of mating processes, the categories of interaction and intersubjectivity must be emphasized, at least for 'modern' societies, as the impact of the social space not only precipitates in form of an agent's practice, but also in form of interacting agents' reciprocal practices of reference.

In mating research, these practices of reference have been conceptualized by the economic term 'exchange', and the competitive character of exchange chances in mating has been variously described with terms like 'mate market', 'partner market' or 'marriage market' (Blau, 1967 ; Blossfeld \& Timm, 2003 ; Bourdieu, 2002). The concept of exchange in mating highlights the relational dimension of interaction processes, as agents reciprocally relate their characteristics in order to detect or explore potential suitability. Based on these exchange relations, the agents involved can form both homogenous and heterogenous couples, if they approach mating interactions strategically. Following Bourdieu's conception, the decisive elements of such exchange processes are generally symbolic in character, and are not necessarily reflected by the agents ${ }^{3}$.

Strategic practices in mating can be expected as, for example, a certain proportion of one gender possess the same preferences, independent from their social position (Bourdieu, 2001 ; South 1991), and the power to realize these preferences is unevenly distributed. 
The resulting competition for traits of common interest can foster strategies and relativize the relevance of lifestyle homophily, especially if the mating interaction proceeds relatively independently from other everyday practices. Bourdieu's concept of strategy ${ }^{4}$ refers not only to individual practices but also to reciprocal classification practices : "The convertibility of the different types of capital is the basis of the strategies aimed at ensuring the reproduction of capital." (Bourdieu, 1986: 253). Hence, alongside the process of confirming life-style congruency, a mating strategy can be conceptualized as the implied conversion chances of an agent's capital into another capital. Bourdieu's example of Le Bal des Célibataires gives insights into this analytical view (Bourdieu, 2002), using the example of Béarnesean first-born men, whose symbolic capital had been devaluated in the 1960s through an opening of the marriage market. Although the female agents certainly possessed particular habitus-based mating preferences, their impact was relativized through the social changes of the time, which led to a significant number of these women preferring men from the city to bachelors from rural regions. Hence, the taste of these women was not treated by Bourdieu as being determined by their position in the general social space, but rather as a function of their position in an extended marriage market. One could state that the female expectation of capital conversion had an impact on both their mating preferences and the resulting couple configurations. Accordingly, reciprocal classification in mating can be described by specific conversion practices that need interactions to be put into effect. Fading these interactional elements out may lead to the fallacy of inferring homophily from homogeneity.

\section{Equivalency as Mode of Reciprocal Classification}

18 In this section, I argue for an extended model of reciprocal classification, a model that takes into account that the dissimilarity of agents involved in mating interactions is not contingent, but structured in a systematic way.

Similarity of inter-actors can be conceptualized as a function of the essential equality of their manifest characteristics (e.g. the same educational degree), but also as a function of the relational equivalency of the symbolically perceived sum of their particular characteristics (e.g. different educational degree and income). De Singly (1987) showed that the negotiation process between potential mates is regulated by two implicit principles : social equivalency and sexual complementarity. Accordingly, a similarity in the 'latent market value' of two partners can correspond to dissimilarity in manifest characteristics. Some agents might possess preferences for other traits to those they possess themselves, a consideration that seems quite obvious when reflecting the discussed gender-specific dimension of traits and trait preferences (see De Singly, 1987).

A concept of equivalency does not contradict Bourdieu's notion of habitus and taste, as he examined the aforementioned case in Béarn from a perspective of a 'market of symbolic exchange relations'. His idea was that it is not actual exchange that underlies mating processes, but rather that exchange takes symbolic forms and refers to symbolic goods. In the market of symbolic goods, the agent's social status - and hence the symbolic representation of their capital configuration - are perceived or sensed as the objects of exchange (Bourdieu, 2002: 229). The symbolic capital can be differentiated in its amount and its structure, its underlying sources. In the perspective of the symbolic goods market, one can hypothesize that agents who are equivalent in the overall volume of their capital, and hence their symbolic capital, are more likely to start an interaction than those who 
differ with regard to their capital volume. This means that a comparable symbolic capital, and hence the same (or higher) capital volume, can facilitate a relationship or marriage in relative independence of its composition. This may take place in the form of rational calculation, as well as through an unconscious adaptation to one's objective chances.

In both cases, equivalencies emerge as classifying practices of the agents involved, based on mutual approval and appreciation. It is an empirical question as to how far these practices also take the form of taste, that is, to what extent they are unconscious and rooted in dispositions. According to Bourdieu, agents adapt to their objective chances : if partners with a different lifestyle are more likely to form a relationship than partners with the same lifestyles, it is in line with Bourdieu's theory that they may adapt to these and hence develop heterophilous preferences. With regard to the example of the marriage market in the Béarn, one could state that market conditions had an impact on the females' sense of their place, inasmuch as their conception of what they could achieve changed. Conversely, those males from urban areas who associated with females from rural areas relativized (consciously or unconsciously) lifestyle similarity in favor of other traits. The resulting couples were dissimilar regarding their lifestyle, but they can be ascribed a certain latent trait equivalency that originated through the evaluations and practices of the agents involved. Therefore, one can conclude that (gender-specific) equivalency of symbolic capital can relativize similarity preference under certain circumstances, and couple formation emerges as a function of "two balanced matrimonial strategies" (De Singly, 1987: 188), which can foster complementary couple configurations.

\section{Empirical Assessment}

\section{Methodological Implications : Observing the Process of Reciprocal Classifications}

Bourdieu's theoretical perspective was not independent from his empirical practice. He did not survey the early phases of encounter, rather the outcome, nor did he observe interactional processes, but instead put an axiom of homophily into place, and he did not intensively discuss the involved agents' subjective perceptions "diverging" from their position in the mating market. The proposed elaboration of the habitus-field perspective on mating processes treats agents as reciprocally classifying each other and their characteristics. Methodologically speaking, agents represent reciprocally classifying entities that must themselves be classified by the scientific observer. However, the previous considerations lead to the methodological postulate of observing interactions instead of individual practices, and of analyzing different traits instead of only one, and of taking the gender dimension of the mating process into account.

These theoretical considerations suggest that interactional data of the men and women involved is needed for an adequate analysis of reciprocal classification processes in mating. Only information on interactions can provide information on the agents' configurations and potential dissimilarities, and hence allow for a (re-)construction of mating processes. Following Bourdieu's "methodological relationalism" (Bourdieu \& Wacquant, 1992:15), the primary task is to objectively construct the research subject, that is, to also provide a quantitative assessment of the particular social phenomenon (Bourdieu, 1985). Questionnaire data commonly used in social sciences do not meet the 
requirement of quantitatively depicting reciprocity in human couple formation, as they are usually restricted to the interviewee. Dyadic surveys only cover existing couples and depend on retrospectively surveyed information regarding the first encounter. Aggregated marriage statistics, which are often used in research on couple formation, do not permit analysis of the first situation of encounter, especially regarding the alternative partners who would have been available at that time. However, if one accepts the restriction to 'stated preferences' (using survey data) or to observing existing couples (using marriage data), this might lead to a miscalculation regarding the relevance of homophilous preferences at the time of the first encounter.

\section{Online Dating : a Tool for the Observation of Dyadic Interactions}

The observation of dyadic partner relationships on online dating sites, and the relations of the characteristics of the agents involved, constitutes a promising opportunity for depicting relational configurations of characteristics (Schmitz et al., 2009). Although this information is essentially a by-product of the data organization of a private provider, it is an effective basis for theory-driven analysis of mating processes.

Technically, a dating site is a relational database in which users and their 'clickstream' actions are recorded. By logging on and entering information (e.g. sex, age, level of education, lifestyle, etc.) into a profile form, a user can take part in the services of the dating site. The graphical user interface of a dating site is used to access the database, i.e. to receive information on other people and to enter into interactions with them. The particular dating site in question allows for a free search, in contrast to matchmaking sites where potential mates are proposed by an algorithm developed by the provider. This database contains real-time information on when a user has visited another user's profile, when a message was sent, and whether this was an initial contact, an answer etc. (Major) online dating sites represent dating and research contexts that, compared to other contexts, are less socially segregated, which permits the isolation of preferences from effects of context on the probability of an encounter (see Bozon \& Héran, 1989). Contact information can be interpreted as practised homophily and heterophily. The relevance of particular resources for initiating and perpetuating an interaction can be assessed using the profile information of the users in question. The real time record of such events allows for the reconstruction of the underlying processual character.

In online dating, profile information functions as a display of symbolic goods and lifestyles, and their impact on mating initiations becomes observable in a new way. It is not possible to analyze the messages' content due to privacy reasons, therefore the phenomenological dimension of the interaction that precipitates in the meaning of a particular message or response cannot be analyzed. However, the online dating design creates the potential to meet the requirements of a refined Bourdieusian model of reciprocal classification processes in mating by means of objective results. It allows for an identification of homogeneity and heterogeneity in dyads and for an interpretation according to lifestyle similarity, equivalency or further sorting mechanisms. 


\section{Methodical Implications : The Classification of Reciprocal Classifications}

From a methodical perspective, reciprocal classification processes correspond to statistical issues. Dyad members and their characteristics are not independent from each other, a fact described as "non-independence" by Kenny, Kashy and Cook (2006). This dependence structure of dyad members can be regarded not only as a statistical problem, but also as a source of substantial variation that needs to be modeled and interpreted. Analyzing the process of assortative mating basically means observing and modeling dyadic agent configurations, and hence the configurations of their characteristics. The task is not to model average agents with unidirectional contacting (as a regression model would suggest), but to find out which typical agent configurations emerge and survive.

For this purpose, I propose to model agent configurations, applying the statistical dependency of the dyads involved, with a finite mixture model (Vermunt \& Magidson, 2003) in order to identify typical dyadic association patterns. The identification of typically occurring dyads is effected by means of the manifest (dis)similarity in characteristics between the interacting users. For this purpose, each characteristic is used once for each dyad member and an optimum of categorical latent classes is searched. This approach is thus very similar to a structural equation model for dyadic data (Kenny, Kashy \& Cook, 2006). The proposed multivariate classification of dyadic data is a way to reduce the complexity of interactions and to facilitate a structural analysis. In contrast to traditional cluster analysis techniques, the latent class classification predicts probabilities of class membership. One can statistically determine the optimal number of classes, and predict the probabilities of variable values within these classes. The proposed dyadic extension of this basic principle consists of a classification of observed interactions of two individuals. Hence not classes of individual users are identified, but classes of dyads.

In the following section, a simplified example for the identification of typical dyadic configurations is presented, and some aspects of the theoretical discussion are examined. The example is based on digital records of contact events between senders and receivers on a major German online dating site. The data used comes from a major German dating platform of the year 2009 (1st of January 2009 - 26th October 2009). It consists of profile information as well as information regarding contact events between users, which are not affected by a matching algorithm. The data structure and its implications are discussed in Schmitz et al. (2009)5.

\section{Dyadic Interaction Classes}

From a simplified Bourdieusian perspective of homophily, one could expect that the only dyads to emerge will be homogenous with regard to the variables used in the model, i.e. that a variable value (e.g. a certain lifestyle) of the sender determines the same variable value of the receiver of a contact. If this were the predominant pattern, the proposed analysis would lead to a class of homogenous dyads (a class with lifestyle "A" of sender and receiver, a class with lifestyle "B" of sender and receiver etc). Another expectation may be that all possible dyadic configurations, and no classes, emerge - meaning that the sender's characteristics do not determine what kind of receiver he or she contacts. If we 
were to observe this, neither the conservative homophily perspective nor the proposed equivalency mode would apply to the data. With regard to the theoretical discussion of a generalized reciprocal classification, this approach also enables to find systematic relations of difference. If the idea of generalized classification holds true, one would expect that dyadic classes also emerge where sender and receiver systematically differ in their characteristics.

31 Furthermore, one can expect that it will make a fundamental difference whether one analyses the first or lasting observed contacts (FOCs or LOCS). The first contact information is significant for describing initial mating preferences, that is, the kind of partner a particular class of user is interested in. The lasting contacts, on the other hand, go some way toward illustrating those couple constellations given a chance of success by their participants, that is, the dyadic classes most likely to lead to a later date or a relationship. Theoretically, one can expect that a plethora of different dyadic configurations emerge in the very first moment of contact, but during the process of interaction, some dyadic configurations can be expected to become extinct. Not all first contacts will be answered, and even if an answer follows the first contact, the third contact can be expected to systematically reduce the types of surviving dyadic configurations. This process goes on until the observations end, that is, the process shifts to other media such as telephone, e-mail or face-to-face meetings. ${ }^{6}$

Several mechanisms can influence these processes of selective survival of dyads. The first mechanisms, as derived from Bourdieu's theory, would be fostered by life-style dispositions, that is, one can assume that dyads that are homogenous with regard to lifestyle will emerge with an initial contact and will tend to survive in the competitive process on the dating market. See Figure 1 for a first assessment of this central consideration. 
Figure 1 : Correlations of Cultural Capital by Interaction Chain

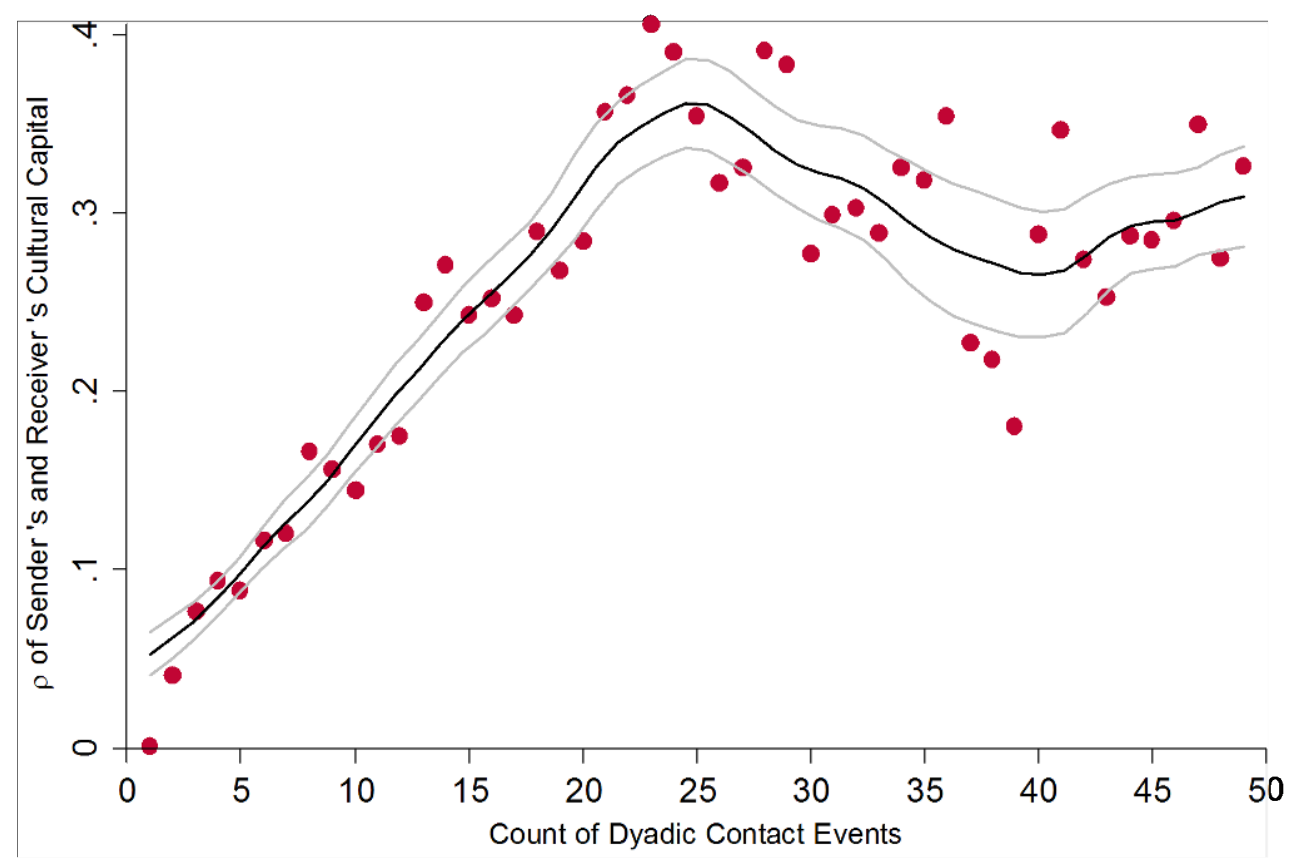

$n=21,048$ (Initiated Dyads). A dot indicates the correlation coefficient $\rho$ for the particular interaction length (1-50). Example : the correlation of senders and receivers cultural capital is approximately zero for first contact events and approximately zero point four for 22 nd events. The black line represents a local polynomial smooth plot. The gray lines indicate the confidence intervals.

Figure 1 shows the average correlations of the cultural capital ${ }^{7}$ of sender and receiver of a message for each contact event from the FOC to the LOC ${ }^{8}$. Obviously, lifestyle works as a strong sorting mechanism, as the average correlation moves from a near zero correlation at the FOC to a correlation of .4 at the 22th interaction event. The graph also describes the process character: the essential proportion of resulting homogeneity does not result from homophily, but from selective extinction of heterogeneous configurations. Up to the 25th interaction event, more culturally dissimilar dyads end the communication than similar dyads. However, the relation between the sender's and the receiver's cultural capital is far from deterministic even at the peak of the interactional chains : only $16 \%$ $(r=0,4)$ of the variance of the receiver's cultural capital can be explained by the sender's cultural capital. Hence, there is still considerable variance between the cultural capital of two interacting users. Furthermore, the average inclination of correlations says nothing about the reciprocal dimension of the process, as it is sufficient if one actor of a dyad has a disposition for lifestyle similarity to explain the emerging pattern. Another possibility is that lifestyle similarity may be a by-product of other preferences. Finally, there is considerable leeway for heterophily, and the question is whether there are further mechanisms that generate couple configurations apart from lifestyle congruencies.

Table 1 : Simplified representation of dyadic interaction classes : First Observed Contacts Between Sender (S) and Receiver (R)

\begin{tabular}{|l|l|l|l|l|}
\hline & Class 1 & Class 2 & Class 3 & Class 4 \\
\hline
\end{tabular}




\begin{tabular}{|c|c|c|c|c|c|}
\hline \multicolumn{2}{|l|}{ Sex } & $\begin{array}{l}\sigma^{\pi} / Q \\
S / R\end{array}$ & $\begin{array}{l}\sigma^{x} / Q \\
S / R\end{array}$ & $\begin{array}{l}P / O^{\top} \\
S / R\end{array}$ & $\begin{array}{l}\text { O/O } \\
S / R\end{array}$ \\
\hline \multicolumn{2}{|l|}{ Age } & $30.6 / 26.2$ & $45.7 / 40.8$ & $26.7 / 31.2$ & $44.9 / 47.6$ \\
\hline \multirow{6}{*}{ Education } & School for basic secondary education & $\rightarrow / \downarrow$ & $\downarrow / \downarrow$ & $\rightarrow / \downarrow$ & $\downarrow / \downarrow$ \\
\hline & Intermediate secondary school & $\rightarrow / \downarrow$ & $\rightarrow / \rightarrow$ & $\downarrow / \rightarrow$ & $\downarrow / \downarrow$ \\
\hline & Apprenticeship & $\uparrow / \uparrow$ & $\downarrow / \downarrow$ & $\uparrow / \uparrow$ & $\downarrow / \downarrow$ \\
\hline & Apprenticeship (crafts) & $\uparrow / \uparrow$ & $\rightarrow / \rightarrow$ & $\uparrow / \uparrow$ & $\rightarrow / \downarrow$ \\
\hline & $\begin{array}{l}\text { University entrance } \\
\text { (Abitur) }\end{array}$ & $\downarrow / \underline{\uparrow}$ & $\underline{\uparrow / \rightarrow}$ & $\rightarrow / \rightarrow$ & $\uparrow / \uparrow$ \\
\hline & University & $\downarrow / \rightarrow$ & $\uparrow / \uparrow$ & $\rightarrow / \rightarrow$ & $\uparrow / \uparrow$ \\
\hline \multirow{3}{*}{ Lifestyle } & Highbrow taste & $\downarrow / \rightarrow$ & $\uparrow / \uparrow$ & $\downarrow / \rightarrow$ & $\uparrow / \uparrow$ \\
\hline & Intermediate taste & $\underline{\uparrow / \rightarrow}$ & $\rightarrow / \uparrow$ & $\uparrow / \uparrow$ & $\downarrow / \downarrow$ \\
\hline & Taste of necessity & $\rightarrow / \rightarrow$ & $\downarrow / \rightarrow$ & $\uparrow / \uparrow$ & $\downarrow / \downarrow$ \\
\hline \multicolumn{2}{|l|}{ Class size } & $28 \%$ & $19 \%$ & $17 \%$ & $13 \%$ \\
\hline
\end{tabular}

Column-wise probabilities : $\downarrow=$ low,$\rightarrow=$ middle, $\uparrow=$ high systematic dissimilarities that may manifest themselves in surviving sender-receiver relations. This consideration again motivates the dissection of the aggregated interaction process into different empirical dyadic configurations using a dyadic classification technique. As discussed in the previous section, the classification was conducted by a latent class analysis, not of individual users, but of dyadic user relations. For purposes of illustration, the presentation of the empirical results is restricted to the profile characteristics sex, age, education, and membership of one of three groups of lifestyle? The description of the emerging dyadic classes consists of first and lasting contacts (see Table 1 and Table 2). In order to qualify the lasting contacts as evidence of dyadic institutionalization, interactions shorter than four events have been excluded ${ }^{10}$. Figure 1 shows the first three events to be somewhat erratic in nature, stabilizing considerably after the fourth event. For reasons of clarity, the depiction is restricted to the four largest dyadic classes.

Table 1 shows the first four dyadic classes of the FOCs, i.e. the four configurations of agents that occur most frequently in FOCs ${ }^{11}$. Class 1 , with $28 \%$ of all FOCs, comprises male senders and female receivers of messages. The average age of the senders is 30.6 years; that of the receivers is 26.2 . The senders are very likely to have an educational level of 'apprenticeship' or 'apprenticeship in crafts ${ }^{12}$. The receivers contacted by them are very likely to have the same educational level or 'Abitur' (the German university entrance qualification). Furthermore, the table shows that men of this class have a high probability of having an 'intermediate taste' and do not contact specifically according to lifestyle, as 
all lifestyles of the female contacts are moderately present. The dyadic class 2 (19\% of all FOCs) also consists of male senders and female receivers but, in comparison to the first identified dyad, the senders and receivers of the second dyad are considerably older. Senders have a high probability of naming Abitur or university as their educational qualification. The women they contact are very likely to be university graduates. The men of this interaction class mostly show a highbrow taste, but they contact women with highbrow and intermediate tastes with the same probability. Class $3(17 \%)$ consists of female senders and male receivers; the FOC is initiated by women who are about 26.7 years old and the contacted men have an average age of 31.2 years. These women mostly contact men who are also doing an apprenticeship or apprenticeship in crafts; but they occasionally also contact men with higher educational qualifications. The women in this interaction class especially contact men who have revealed a similar taste in their profile presentation according to lifestyle information. Class $4(13 \%)$ is also characterized by women (average age : 44.9 years) contacting men (average age : 47.6). In this class, it is striking that there is a high homophily regarding education and lifestyle. Women of this interaction class exclusively contact men who also have a high educational qualification and a highbrow lifestyle. On the whole, the majority of FOCs are initiated by men, which conforms to previous research results that characterize men as the more active sex (see Schmitz et al., 2011) ${ }^{13}$.

Table 2 displays the four largest latent classes of LOC. It becomes clear that, in general, average probabilities occur much more rarely, and therefore a blurring in configurations of characteristics can be observed less often. The overall image is more homogenous than in the case of the initial contact.

The first dyadic interaction class is again constituted of men who contact women. Both sexes are very likely to show an intermediate educational level and an intermediate lifestyle. The second dyadic class, with female senders who have an intermediate educational level and lifestyle, most often contacts men with the same educational level and lifestyle or, alternatively, men who are better educated and show a highbrow taste. Although a causal interpretation is not possible, one can hypothesize that those women might employ their relative youth in order to realize a higher educational status and a highbrow taste in the counterpart. As this class contains agents who have exchanged several messages and therefore, one can assume, expressed their mutual appreciation, the men and women in question can be interpreted as equivalent regarding their symbolic market value on this partner market. The third interaction class is constituted of men and women who have a high educational level and a highbrow lifestyle. The fourth class shows a similar pattern. It seems as if men have to display at least an average education to become a part of an equivalency relationship.

Table 2 : Simplified representation of dyadic interaction classes : Lasting Observed Contacts Between Sender (S) and Receiver (R)

\begin{tabular}{|c|c|c|c|c|}
\hline & Class 1 & Class 2 & Class 3 & Class 4 \\
\hline Sex & $\begin{array}{l}\sigma^{x} / Q \\
\text { S/R }\end{array}$ & $\begin{array}{l}\text { \%/O } \\
\text { S/R }\end{array}$ & $\begin{array}{l}\mathrm{O}^{x} / 9 \\
\mathrm{~S} / \mathrm{R}\end{array}$ & $\begin{array}{l}\text { O/O" } \\
\text { S/R }\end{array}$ \\
\hline Age & $\mathbf{3 1 . 0} / 25.5$ & $26.7 / 31.5$ & $44.5 / 38.7$ & 39.0/46.3 \\
\hline
\end{tabular}




\begin{tabular}{|l|l|l|l|l|l|}
\hline \multirow{5}{*}{ Education } & School for basic secondary education & $\downarrow / \downarrow$ & $\downarrow / \downarrow$ & $\downarrow / \downarrow$ & $\downarrow / \downarrow$ \\
\cline { 2 - 6 } & Intermediate secondary school & $\downarrow / \downarrow$ & $\downarrow / \downarrow$ & $\downarrow / \downarrow$ & $\downarrow / \downarrow$ \\
\cline { 2 - 6 } & Apprenticeship & $\uparrow / \uparrow$ & $\uparrow / \uparrow$ & $\downarrow / \downarrow$ & $\downarrow / \downarrow$ \\
\hline & Apprenticeship (crafts) & $\uparrow / \uparrow$ & $\uparrow / \uparrow$ & $\downarrow / \rightarrow$ & $\rightarrow / \downarrow$ \\
\cline { 2 - 6 } & $\begin{array}{l}\text { University entrance qualification } \\
\text { (Abitur) }\end{array}$ & $\downarrow / \uparrow$ & $\downarrow / \uparrow$ & $\uparrow / \uparrow$ & $\uparrow / \uparrow$ \\
\cline { 2 - 6 } & University & $\downarrow / \downarrow$ & $\rightarrow / \uparrow$ & $\uparrow / \uparrow$ & $\uparrow / \uparrow$ \\
\hline \multirow{5}{*}{ Lifestyle } & Intermediate taste & $\downarrow / \downarrow$ & $\rightarrow / \uparrow$ & $\uparrow / \uparrow$ & $\uparrow / \uparrow$ \\
\hline & Highbrow taste & $\uparrow / \uparrow$ & $\uparrow / \rightarrow$ & $\rightarrow / \rightarrow$ & $\downarrow / \downarrow$ \\
\hline & Taste of necessity & $\rightarrow / \downarrow$ & $\rightarrow / \rightarrow$ & $\downarrow / \downarrow$ & $\downarrow / \downarrow$ \\
\hline \multirow{5}{*}{ Class size } & $25 \%$ & $20 \%$ & $18 \%$ & $11 \%$ \\
\hline
\end{tabular}

COLUMN-WISE PROBABILITIES : $\downarrow=$ LOW,$\rightarrow=$ MIDDLE, $\uparrow=$ HIgH

In this particular example, all of the considered variables, not merely lifestyle, seem to have a relevant influence on couple constitution. This illustrates that even if lifestyle is taken into account, other traits (especially age) are also relevant in reciprocal classification processes. It becomes apparent that the significance of lifestyle varies according to age and sex. Older women, for example, seem to be more discriminating regarding the lifestyle and education of a potential partner, right from the outset. This might be explained by a selection of those agents in the virtual dating market, as the conventional range of options for older, highly educated women cannot meet their expectations and, therefore, they use the Internet to compensate for this without having to lower their aspiration level. Younger women of the sample, by contrast, can be characterized by a preference for manifest similarities, and also by the fact that they remain in relatively stable interactional relations with more highly educated, highbrow men who are about five years older than themselves ${ }^{14}$.

Evidently, during the course of the interaction, characteristics, as well as their carriers, are gender-specifically classified. For example, less-educated men are rated down on the dating market, but less-educated women are not. Education and lifestyle seem to become cumulatively more important and more selective during the course of the interaction, as has been already shown in the descriptive section. Due to the reciprocity of the interactions, the agents' tastes increasingly find expression in the resulting couple configurations, generating specific dyadic configurations. In this cumulative process of decomposition, women's education and preferences for lifestyle in particular seem to work as a decisive filter. The fact that older men in the LOC classes are much more similar to their female contacts can be mainly put down to the explicit preferences of the women involved, and less to male preferences. Hence, an axiom of predominant lifestyle homophily would not be sufficient to describe this outcome. 
To conclude, even within the early process of interaction, agents cumulatively decompose the market through their reciprocal classification practices. These classification practices do not just stem from homophilous lifestyle preferences, but also from dissimilarity preferences that generate homogeneity in the aggregate and that partially foster dissimilar couple configurations. The representations of the analysis potential of dyadic interaction using finite mixing models are only exemplary, and restricted to a small number of variables, but nevertheless they show that agents reproduce social barriers in the practice of contacting and responding, despite the potential lack of geographic and institutional selectivity on the dating site analyzed. In the continuing process of reciprocal classification, these barriers mutually reinforce one another and result in specific dyadic configurations that have a higher chance of prolonging their interactional chain into an offline context and forming a relationship, thereby also reproducing the gender-specific value of the characteristics contributing to the interaction.

\section{Conclusion}

41 Bourdieu's conclusive solution of the so-called micro-macro-problem (e.g. Alexander \& Giesen, 1987), especially in form of his famous works on lifestyle-shaped practice, may suggest that homogeneity and homogamy can be easily reduced to homophilous lifestyle preferences. However, interactions between men and women who are equipped with different and differently valued forms of capital do not necessarily and directly form homogenous couples. Generalizing Bourdieu's view on mating from lifestyle homophily and homogeneity to a gender-specific reciprocal classification process enables a theoretical assessment of the characteristics and preferences of agents who may differ from one another in certain traits. Ignoring these perspectives would foster a deterministic and static interpretation of a Bourdieusian sociology of mating. However, to what extent reciprocal classifications follow preferences for, or lead to, the same lifestyle has to be shown empirically by studying interaction processes. In this article, an empirical classification of online dating interactions was conducted on the basis of dyadic data, and illustrated by a simplified example of application. The usage of dyadic interaction data on an online dating site enabled the interpretation of contact and answer events as reciprocal acts of classification, and allowed for the observation of the relevance of different characteristics in the course of the agents' association practice.

It was shown that agents segment the partner market in the course of interactions in form of a "reciprocal un-mixing" of the observed dyads regarding their homogeneity in education and lifestyle over the course of time. The emerging dyadic classes did increasingly show a similar lifestyle pattern in the course of messaging interaction. However, education and lifestyle proved to be socio-spatially variable in their relevance to classification acts ; particularly older, highly educated women seem to put a special emphasis on similarity in lifestyle and education. The example highlights the fact that similarity preferences do not deserve the status of an unquestioned axiom, a consideration that Bourdieu himself presented in his analyses of the bachelors' ball in Béarn (Bourdieu, 2002). Hence, similarity within an existing couple cannot be reduced to a general mode of homophilous agency, but rather has to be conceptualized as a reciprocal process, one which is also dependent on the gender-specific symbolic capital of the involved agents. This does not suspend the explanatory power of the habitus concept, but instead highlights the processual character of homophily in mating. In the course of 
'romantic interactions', habitus dissimilarity does not exclude a contact event ab initio, but takes effect processually and cumulatively over the course of interaction. The use of Internet dating data allows this process character to be worked out differentially, shedding light on the mating mechanisms driven by habitus. Further research should also assess to what extent these cumulative processes are intensified, for example in the early stages of a realized relationship, and how partners reciprocally influence each other towards the adoption of a common lifestyle. Questions like these cannot be analyzed observing an online dating market, but need offline assessment. Nevertheless, a consideration of an elaborated Bourdieusian model of reciprocal classification may generate insights for the offline process of partnership institutionalization. In concrete terms, future quantitative research should use dyadic data (e.g. of existing couples) and be aware of its methodical implications and possibilities. Qualitative analysis should assess the concept of equivalency relations from a perspective of its subjective meaning, an approach that can be integrated within triangulated online dating research.

Although this article focused on the methodological implications of online dating markets for a Bourdieusan sociology of mating, it may also be of relevance to a critical appraisal of this new medium. Such a perspective could emphasize that it makes little sense to proclaim the resolution of class differences through the digitization of social life. The Internet might shape human practices and interactions in specific ways, but there is no reason to assume that it suspends the fundamental parameters of the social. Agents still classify other agents by patterns of (non-)interaction and, in doing so, (re-) create social classes. Another question may arise as a result of these considerations : will online dating in fact foster the development and amplify the degree of class-based stratification in our society, as it represents a technology of unforeseen possibilities for the reciprocal classification of humans?

\section{BIBLIOGRAPHY}

ALEXANDER Jeffrey C. \& GIESEN Bernhard (1987). From reduction to linkage : the long view of the micromacro debate, in Alexander Jeffrey C., Giesen Bernhard, Münch Richard \& Smelser Neil J. (ed.), The Micro-Macro Link, Berkeley, University of California Press, pp. 1-42.

BENZÉCRI Jean-Pierre et collaborateurs (1973). L'analyse des données. L'analyse des correspondances, Paris, Dunod.

BENZÉCRI Jean-Pierre (1992). Correspondence Analysis Handbook, New York, Dekker.

BERGSTRÖM Marie (2011). “La toile des sites de rencontre en France. Topographie d'un nouvel espace social en ligne”, Réseaux, 166, pp. 225-260.

BLAU Peter M. (1967). Excursus on Love, in Exchange and Power in Social Life, London, John Wiley \& Sons, pp. 76-85.

BLOSSFELD Hans-Peter \& TIMM Andreas (ed.) (2003). Who Marries Whom ? Educational systems as Marriage Markets in Modern Societies, Dordrecht, Kluwer Academic Publishers. 
BLOSSFELD Hans-Peter (2009). “Educational assortative marriage in comparative perspective”, Annual Review of Sociology, 35, pp. 513-530.

BOTTERo Wendy (2009). "Relationality and social interactions", The British Journal of Sociology, 60 (2), pp. 399-420.

BOURDIEU Pierre (1963). “The Attitude of the Algerian Peasant Toward Time”, in Pitt-Rivers Julian A. (ed.), Mediterranean Countrymen, Paris, Mouton, pp. 55-72.

BOURDIEU Pierre (1973). "Cultural Reproduction and Social Reproduction”, in Brown Richard K. (Ed.), Knowledge, Education, and Cultural Change : Papers in the in the Sociology of Education, London, Tavistock, pp. 71-112.

BOURDIEU Pierre (1980). Le sens pratique, Paris, Minuit.

BOURDIEU Pierre (1984). Distinction : A Social Critique of the Judgement of Taste, Cambridge, MA, Harvard University Press.

BOURDIEU Pierre (1985). "The Social Space and the Genesis of Groups”, Theory and Society, 14(6), pp. 723-744.

BOURDIEU Pierre (1986). “The forms of capital”, in Richardson John (ed.), Handbook of Theory and Research for the Sociology of Education, New York, Greenwood, pp. 241-258.

BOURDIEU Pierre (1987). "What Makes a Social Class ? On the Theoretical and Practical Existence of Groups", Berkeley Journal of Sociology : A Critical Review, 31, pp. 1-18.

BOURDIEU Pierre (1990). In Other Words : Essays towards a Reflexive Sociology, Oxford, Polity.

BOURDIEU Pierre \& WACQUANT Loïc (1992). An Invitation to Reflexive Sociology, Chicago and London, University of Chicago Press.

BOURDIEU Pierre (1997). “Eine sanfte Gewalt. Pierre Bourdieu im Gespräch mit Irene Dölling und Margareta Steinrücke”, in Dölling Irene and Krais Beate (ed.), Ein alltägliches Spiel. Geschlechterkonstruktion in der sozialen Praxis, Frankfurt a. M., Suhrkamp, pp. 218-30. BOURDIEU Pierre (1998). Practical Reason, Palo Alto, CA, Stanford University Press. BOURDIEU Pierre (2001). Masculine Domination, Oxford, Polity. BOURDIEU Pierre (2002). Le bal des célibataires, Paris, Seuil. BOZON Michel \& HÉRAN François (1989). "Finding a spouse : a survey of how French couples meet”, Population, An English Selection, 1, pp. 91-121.

DE SINGLY François (1987). “Théorie critique de l'homogamie”, L'Année sociologique, 37, pp. 181-205. ELLISON Nicole, HEINO Rebecca \& GIBBS Jennifer (2006). “Managing impressions online. Selfpresentation processes in the online dating environment", Journal of Computer-Mediated Communication, 11. Retrieved on October 13, 2011.

KENNY David A., KASHY Deborah A. \& сооK William L. (2006). Dyadic Data Analysis, New York, The Guilford Press.

KING Anthony (2000). "Thinking with Bourdieu Against Bourdieu : A 'Practical' Critique of the Habitus", Sociological Theory, 18(3), pp. 417-433.

NAGEL Ineke, GANZEBOоM Harry B. G. \& KALMijn Matthijs (2011). "Bourdieu in the network: The influence of high and popular culture on network formation in secondary school", Kölner Zeitschrift für Soziologie und Sozialpsychologie, 51, pp. 424-446. 
SAUTTER Jessica M., TIPPETT Rebecca M. \& MORGAN S. Philip (2010). “The social demography of Internet dating in the United States", Social Science Quarterly, 91(2), pp. 554-575.

SCHMITZ Andreas, SKOPEK Jan, SchUlZ Florian, KLEIN Doreen \& BLOSSFELD, Hans-Peter (2009).

"Indicating mate preferences by mixing survey and process-generated data. The case of attitudes and behaviour in online mate search", Historical Social Research, 34(1), pp. 77-93.

SCHMITZ Andreas, SACHSE-THÜRER Susan, ZILLMANN Doreen \& BLOSSFELD HANS-PETER (2011). "Myths and facts about online mate choice. Contemporary beliefs and empirical findings", Zeitschrift für Familienforschung - Journal of Family Research, 23(3), pp. 358-381.

SKOPEK Jan (2012). Partnerwahl im Internet - Eine quantitative Analyse von Strukturen und Prozessen der Online-Partnersuche, Wiesbaden, VS Verlag für Sozialwissenschaften.

soUTH Scott J. (1991). “Sociodemographic differentials in mate selection preferences", Journal of Marriage and the Family, 53(4), pp. 928-940.

VERMUNT Jeroen K. \& MAGIDSON Jay (2003). "Latent class models for classification”, Computational Statistics and Data Analysis, 41(3-4), pp. 531-537.

ZILLMANN Doreen, SCHMITZ Andreas \& BLOSSFELD Hans-Peter (2011). "Lügner haben kurze Beine. Zum Zusammenhang unwahrer Selbstdarstellung und partnerschaftlicher Chancen im OnlineDating“, Zeitschrift für Familienforschung - Journal of Family Research, 23(3), pp. 291-318.

\section{NOTES}

1. My thanks for helpful suggestions go to Lydia Kleine, Markus Zielonka, Marie Bergström, and William Tayler, as well as to the editors and reviewers.

2. In Distinction, this relevance of habitus is well illustrated using pictures of couples, an impression that can be appreciated when viewing the striking congruence of couples in real life, for example in clothing and posture - all the more so if one observes the social reaction towards incongruities in a couple (Bourdieu, 1984).

3. Although the situations generated by a (virtual) mate market surely foster practices of reflected choice.

4. A strategy can be seen as (i) an intentional action, whose goal is the realization of a preferably attractive partner with the aid of convertible capital. The sense of one's own position does not automatically imply the preference for similarity regarding a maximum of characteristics or lifestyle features - when and inasmuch as mating actually constitutes a choice, i.e. if the "habitus driven' moment takes a back seat to rational calculations. Moreover, strategy can (ii) also refer to the habitus-based (or practical) adoption of objective prerequisites (Bourdieu 1980) and foster a sense of one's place "as a sense of what one can or cannot 'permit oneself' " (Bourdieu, 1985 : 728).

5. Skopek (2012) shows that the particular dating site is not a niche service, but rather comprises a comprehensive representation of users with very different characteristics.

6. As the data available includes information collected prior to the analyzed sample of 2009 (the recording process started 2001), it was possible to address the problem of left-censoring.

7. The cultural capital was constructed using multiple correspondence analysis (cf. Benzécri, 1973 ; 1992). The variables used were hobbies and lifestyle items (e.g. furnishing, shopping locations, clothing style, variables of social capital) as surveyed in the user's profiles.

8. Interaction length higher than 50 was excluded due to small $n$.

9. Lifestyle groups were constructed heuristically based on the results of the multiple correspondence analysis: highbrow taste with high economic and cultural capital, taste of 
necessity with low resources and an intermediate lifestyle with an intermediate manifestation of both capital axes.

10. This choice is surely contingent, as a more restrictive sub-population could also have been defined; however, it is a conservative approach, in order to check whether the sub-population starting with four contact events already shows an interactional pattern that diverges from the first contact pattern.

11. Depending on the variables used, the statistical optimum of the class solution amounted to up to 13 further classes (i.e. configurations of agents) that are not displayed here.

12. Germany has a differentiated system of vocational training: apprenticeships combine learning 'on the job' with an academic education geared towards the particular field of work in question. The qualifications thus earned are officially recognized and universal for that field, be it in the broader service industry or in traditional handicrafts. The users in question have completed an apprenticeship, and are therefore qualified practitioners of their profession.

13. Note again that only the four largest classes are reported ( $47 \%$ male initiated dyads and $30 \%$ female initiated dyads)

14. It is possible that the described effects are a by-product of variables not considered in this example. This could be assessed using the full information of the user's profile, for example presence of a picture, weight, height, presence of children etc.

\section{ABSTRACTS}

Although Pierre Bourdieu's works treated partnership formation, the processual and intersubjective character of mating and the gender-specific resources convoked in reciprocal evaluations and rating practices are blind spots in his perspective based on homophilous lifestyle preferences. Consequently, this article develops a framework of mating processes extending Bourdieu's theory and thereby provides a starting point for empirical assessments. Using data taken from a major German online dating provider, the article shows that, due to the dyadic nature of encounters, the pressure of self-presentation and choice and the high degree of competition between many potential partners, online dating is an ideal-type market that enables the detailed study of classificatory processes. Beginning with an elaboration towards a general model of reciprocal classification in mating, refining the Bourdieusian model of partnership formation, the paper explains the data's structure and its operationalization from methodological and methodical points of view. Finally, a simplified, empirical application of a model of classificatory mating practices is presented and discussed, suggesting that homogeneity (rather than homophily) is reinforced, not undermined, by the technical conditions of online interaction.

Si Pierre Bourdieu a bien évoqué les mécanismes de la formation du couple, le caractère processuel et inter-subjectif de la rencontre, comme les ressources spécifiques aux différents genres qui sont mobilisées dans les évaluations réciproques et dans les jugements sentimentaux demeurent des angles morts de sa perspective, fondée sur l'idée d'une homophilie des styles de vie. Cet article présente un cadre théorique pour penser les processus de formation du couple qui élargit la théorie de Bourdieu et constitue ainsi un point de départ pour des investigations empiriques. A partir de données issues de l'un des principaux sites de rencontre allemand, il montre que, du fait de la nature dyadique de la rencontre, de la pression liée à la présentation de 
soi et à la question du choix, ainsi que du haut degré de compétition entre les partenaires potentiels, les sites de rencontre constituent un marché idéal-typique qui autorise l'étude fine des processus de classification. Nous poserons tout d'abord le cadre d'un modèle général de classification réciproque dans la formation du couple, en raffinant le modèle bourdieusien, avant de présenter la structure des données et leur intérêt méthodologique et méthodique. Enfin, une application empirique simplifiée d'un modèle de rencontre et de classification est présenté. Il suggère que l'homogénéité (plutôt que l'homophilie) est renforcée, et non sapée, par les conditions techniques de l'interaction sur Internet.

INDEX

Mots-clés: marché matrimonial, rencontres en ligne, Bourdieu, classification réciproque, données dyadiques

Keywords: partner market, online dating, Bourdieu, reciprocal classification, dyadic data

\section{AUTHOR}

\section{ANDREAS SCHMITZ}

University of Bamberg, Chair of Sociology I 